\title{
Umpikauden karkearehun vaikutus poikimahalvausriskiin
}

\author{
Annu Palmio, Aura Mikkonen \\ Luonnonvarakeskus, Vihreä teknologia, Halolantie 31 A, 71750 Maaninka, etunimi.sukunimi@luke.fi
}

Poikimahalvaus on yksi yleisimmistä lypsylehmien sairauksista Suomessa. Poikimahalvaukseen sairastuu noin 5\% lypsylehmistä ja poikimisen jälkeen subkliinisesta hypokalsemiasta eli piilevästä poikimahalvauksesta kärsii jopa puolet useamman kerran poikineista lehmistä. Piilevä poikimahalvaus ei aiheuta selviä halvausoireita, mutta heikentää lehmän yleiskuntoa ja lisää alttiutta useille sairauksille. Poikimahalvausriskiin vaikuttaa lehmän umpikauden ruokinta. Suomalaiset nurmisäilörehut eivät useinkaan ole kivennäskoostumukseltaan hyviä rehuja ummessa oleville lehmille. Poikimahalvausriskiin vaikuttava kationi-anionitasapaino eli DCAD-arvo (DCAD $\left.=\left(\mathrm{K}^{+}+\mathrm{Na}^{+}\right)-\left(\mathrm{Cl}^{-}+\mathrm{S}^{2-}\right)\right)$ on nurmisäilörehuun perustuvissa

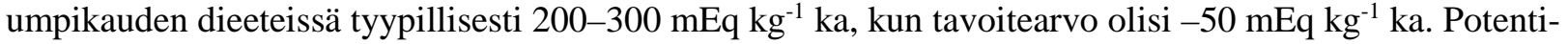
aalinen karkearehuvaihtoehto nurmisäilörehun tilalle on kokoviljasäilörehu. Kokoviljasäilörehussa kalsium- ja kaliumpitoisuudet sekä DCAD-arvo ovat tyypillisesti nurmisäilörehua matalammat.

Luke Maaningalla tehtiin lypsylehmien ruokintakoe, jonka tarkoituksena oli selvittää voidaanko poikimahalvausriskiä pienentää käyttämällä umpikauden ruokinnassa perinteisen nurmisäilörehun sijaan kokoviljasäilörehua. Nurmiruokinta koostui toisen sadon timotei-nurminatasäilörehusta (D-arvo $659 \mathrm{~g} \mathrm{~kg}^{-1} \mathrm{ka}^{\text {) }}$. Kokoviljaruokinnassa oli vehnäkokoviljasäilörehua (D-avo $600 \mathrm{~g} \mathrm{~kg}^{-1} \mathrm{ka}$ ), jota matalan raakavalkuaispitoisuuden takia täydennettiin rypsillä. Lisäksi ruokinnat sisälsivät saman määrän umpikauden kivennäistä.

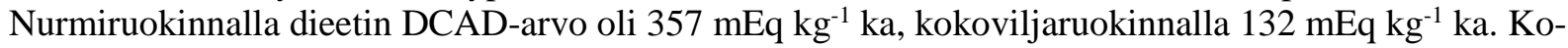
keessa oli mukana 54 holstein- ja ayshirerotuista lehmää ja hiehoa. Lehmät siirtyivät koeruokinnoille heti umpeen laitettaessa. Hiehot olivat koeruokinnoilla kaksi viimeistä tiineyskuukautta. Ruokinta oli rajoitettu, niin että eläinten energian saanti oli noin $90 \mathrm{MJ} \mathrm{pv}^{-1}$. Kaikki koe-eläimet tunnutettiin samalla tavalla. Veren kalsiumpitoisuuden määrittämistä varten verinäytteet otettiin kaksi viikkoa ennen odotettua poikimista sekä 10-24 tuntia poikimisen jälkeen.

Kaikkien koe-eläinten veren kalsiumpitoisuus oli normaalilla tasolla (2,1-2,5 mmol l-1 $)$ ennen poikimista otetuissa näytteissä. Poikimisen jälkeen kalsiumpitoisuudet laskivat. Piilevä poikimahalvaus (Ca 1,4-2,0 $\mathrm{mmol} \mathrm{l}^{-1}$ ) oli 15 lehmällä. Yhdellä lehmällä veren kalsiumpitoisuus oli alle kliinisen poikimahalvauksen raja-arvon $\left(<1,4 \mathrm{mmol} \mathrm{l}^{-1}\right)$. Poikimisen jälkeiseen veren kalsiumpitoisuuteen vaikutti odotetusti lehmän poikimakerta, sillä useamman kerran poikineiden kalsiumpitoisuus oli merkittävästi ensikoita matalampi. Umpikauden ruokinnalla ei ollut vaikutusta veren kalsiumpitoisuuteen eikä alkulypsykauden tuotokseen. Poikimisen jälkeistä veren kalsiumpitoisuuden laskua selitti parhaiten alkulypsykauden tuotos; kun ensimmäisen viikon keskimääräinen päivätuotos nousi yhden kilon, niin kalsiumpitoisuus laski $0,02 \mathrm{mmol} \mathrm{l}^{-1}$.

Tämän tutkimuksen perusteella kokoviljasäilörehu soveltuu umpikauden ruokintaan, mutta se ei pienennä poikimahalvausriskiä tyypilliseen nurmisäilörehuun verrattuna.

Asiasanat: poikimahalvaus, umpikauden ruokinta, DCAD-arvo 


\section{Johdanto}

Poikimahalvaus on lypsylehmien yleisin aineenvaihduntasairaus, johon Suomessa sairastuu noin 5\% eläimistä (Pyörälä ja Tiihonen 2005). Lisäksi subkliinisesta hypokalsemiasta eli piilevästä poikimahalvauksesta saattaa kärsiä jopa puolet useamman kerran poikineista lehmistä (Reinhardt ym. 2011). Poikimahalvaus on kalsiumaineenvaihdunnan häiriö, mikä on tavallisimmin seurausta lehmän äkillisestä, runsaasta kalsiumin menetyksestä ternimaitoon. Kliinisen poikimahalvauksen (veren kokonaiskalsiumpitoisuus < $1,4 \mathrm{mmol} \mathrm{l}^{-1}$ ) oireita on yleinen lihasheikkous, ruokahalun häviäminen, märehtimisen ja suoliston toiminnan lakkaaminen sekä ruumiin lämpötilan lasku. Lihasheikkous etenee halvaukseen, ja lopulta ilman hoitoa lehmä menehtyy. Poikimahalvauksesta saattaa lisäksi seurata mm. jälkeisten jääminen, kohdun ulosluiskahdus, juoksutusmahasairauksia ja utaretulehduksia (Pyörälä ja Tiihonen 2005, Blanc ym. 2014). Hoitokustannusten lisäksi tuottajan taloudellisia tappioita lisää se, että poikimahalvauksen seurauksena lehmän elinaikaistuotos laskee. Piilevästä poikimahalvauksesta puhutaan, kun selviä kliinisiä halvausoireita ei ole, mutta veren kokonaiskalsiumpitoisuus on alle normaalin (välillä 1,4-2 $\mathrm{mmol} \mathrm{l}^{-1}$ ). Piilevä poikimahalvaus heikentää lehmän vastustuskykyä, jolloin alttius useille sairauksille kuten utaretulehdukselle lisääntyy (Goff 2014).

Poikimahalvausriskiin vaikuttaa mm. lehmän ikä, rotu, kuntoluokka ja umpikauden ruokinta. Ruokinnallisista tekijöistä etenkin kalsiumin ja kaliumin liikasaanti sekä magnesiumin puute lisäävät poikimahalvausriskiä (Pyörälä ja Tiihonen 2005). Happaman dieetin eli anioniylimäärän rehussa ummessaoloajan loppuvaiheessa on havaittu ehkäisevän poikimahalvausta. Rehun sisältämien kivennäisaineiden positiivisten ja negatiivisten sähkövarausten perusteella voidaan laskea niin sanottu kationi-anionitasapaino eli DCADarvo (DCAD dietary cation-anion difference). DCAD-arvon laskentaan on useita kaavoja, joista yksinkertaisin ja toimivimmaksi havaittu on $\left(\mathrm{K}^{+}+\mathrm{Na}^{+}\right)-\left(\mathrm{Cl}^{-}+\mathrm{S}^{2-}\right)$ (Lean ym. 2013). Ennen poikimista dieetin DCAD-arvon tulisi olla mahdollisimman alhainen, suositeltu tavoitearvo on $-50 \mathrm{mEq} \mathrm{k^{-1 }} \mathrm{ka}_{\text {(Goff ja }}$ Horst 2003). Leanin ym. (2006) meta-analyysin perusteella umpikauden ruokinnan DCAD-arvon pieneneminen pienentää lineaarisesti poikimahalvausriskiä.

Suomalaiset nurmisäilörehut eivät useinkaan ole kivennäskoostumukseltaan hyviä rehuja ummessa oleville lehmille. Nurmisäilörehuun perustuvissa umpikauden dieeteissä DCAD-arvo on tyypillisesti 200-300 $\mathrm{mEq} \mathrm{kg}{ }^{-1} \mathrm{ka}$ (Saarijärvi ja Kananen 2012). Potentiaalinen karkearehuvaihtoehto nurmisäilörehun tilalle on kokoviljasäilörehu. Kokoviljasäilörehussa kalsium- ja kaliumpitoisuudet sekä DCAD-arvo ovat tyypillisesti nurmisäilörehua matalammat. Luke Maaningalla tehtiin ruokintakoe, jonka tarkoitus oli selvittää, voidaanko poikimahalvausriskiä pienentää eli veren kalsiumpitoisuuden laskua estää käyttämällä umpikauden ruokinnassa perinteisen nurmisäilörehun sijaan kokoviljasäilörehua.

\section{Aineisto ja menetelmät}

Kokeessa käytetyt karkearehut korjattiin Maaningalla kesällä 2015. Toisen sadon timotei-nurminatasäilörehu niitettiin 14.8. ja säilöttiin noin vuorokauden esikuivatuksen jälkeen laakasiiloon ja salvosäilöön. Vehnäkokoviljasäilörehu (lajike Puntari) korjattiin suoraniittopäällä varustetulla ajosilppurilla aikaisessa takinatuleentumisvaiheessa 26.8. ja säilöttiin laakasiiloon. Molempien karkearehujen säilöntään käytettiin muurahaishappopohjaista säilöntäainetta (AIV 2 Plus) 5 l tonni $^{-1}$ tuoretta rehua.

Kokeessa oli kaksi erilaista umpikauden ruokintavaihtoehtoa, perinteinen nurmiruokinta sekä kokoviljaruokinta. Nurmiruokinta koostui toisen sadon timotei-nurminatasäilörehusta. Kokoviljaruokinnassa oli vehnäkokoviljasäilörehua, jota matalan raakavalkuaispitoisuuden takia täydennettiin rypsillä. Rypsilisän määrä valittiin siten, että kokoviljaruokinnan pötsin valkuaistase (PVT) saatiin nostettua negatiivisesta nollaksi. Lisäksi ruokinnat sisälsivät saman määrän jauheista umpikauden kivennäistä karkearehuun sekoitettuna.

Ruokintakoe suoritettiin Luke Maaningan tutkimuspihatossa kesän ja syksyn 2016 aikana. Kokeessa oli 54 eläintä, joista 14 oli ensimmäisen kerran poikivia hiehoja, 18 toisen kerran poikivia, 12 kolmannen kerran poikivia ja 10 yli kolmannen kerran poikivia. Eläimistä 40 oli holstein- ja 14 ayrshirerotuisia. Koe-eläimet 
jaettiin pareihin poikimakerran ja odotetun poikimapäivän perusteella. Kunkin parin toinen eläin siirtyi heti umpeutusvaiheessa satunnaisesti nurmiruokinnalle ja toinen kokoviljaruokinnalle. Eläimet umpeutettiin tuotoksen perusteella, niin että tavoiteltu umpikauden pituus oli 40-60 päivää. Hiehot siirtyivät koeruokinnoille kaksi kuukautta ennen odotettua poikimista.

Koe-eläimet olivat 24-lehmän pihatto-osastolla ja saivat koekarkearehuseoksen vaaoilla varustetuista rehukupeista (Rouhage Intake Control, Insentec, Hollanti), joita oli yksi kahta eläintä kohden. Ruokinta oli yksilöllisesti rajoitettu, niin että tavoiteltu energian saanti oli karkearehuseoksesta $90 \mathrm{MJ} / \mathrm{eläin/pv}$. Hiehot saivat lisäksi 1 kg/pv ohraa väkirehukioskista. Lehmillä tunnutusruokinta ohralla ja rypsillä aloitettiin kolme viikkoa ennen odotettua poikimista. Myös hiehojen väkirehuruokinta oli kolme viimeistä tiineysviikkoa samanlainen kuin lehmillä ja kaikki koe-eläimet saivat odotetun poikimisen aikaan väkirehua $2 \mathrm{~kg} / \mathrm{pv}$ (ohra $1,5 \mathrm{~kg}$ ja rypsi $0,5 \mathrm{~kg}$ ).

Eläimet poikivat oljella kuivitetuissa poikimakarsinoissa ja saivat heti poikimisen jälkeen vapaasti lypsävien seosrehua sekä 2 kg/pv täysrehua. Poikimakarsinoissa lehmät olivat yhdessä vasikan kanssa 0-10 tuntia. Useamman kerran poikineita eläimiä pidettiin parsiosastolla vähintään ensimmäiset neljä tuotospäivää, minkä aikana eläinten lämpötila mitattiin päivittäin peräsuolesta. Ensimmäisen kerran poikineet eläimet siirtyivät poikimakarsinoista suoraan 24 lehmän pihatto-osastolle, jossa saivat vapaasti lypsävien seosrehua rehukupeista sekä 2 kg/pv täysrehua rehukioskista. Useamman kerran poikineet eläimet siirtyivät parsiosastolta ensikoiden kanssa samalle pihatto-osastolle.

Eläimiltä otettiin verinäytteet häntälaskimosta kaksi viikkoa ennen odotettua poikimista sekä 10-24 tuntia poikimisen jälkeen. Lehmät lypsettiin poikimisen jälkeen kahdesti päivässä ja maitotuotos mitattiin 60 ensimmäisen tuotospäivän ajan. Pihatto-osastolla lehmien rehunkulutus mitattiin päivittäin umpikaudella sekä 60 ensimmäisen tuotospäivän ajan. Poikimakarsinoissa ja parressa oloajalta lehmiltä mitattiin maitotuotos, mutta ei syöntiä.

Umpikaudella käytetyistä karkearehuista otettiin näytteet kaksi kertaa ja väkirehuista kerran viikossa. Saman kuukauden näytteet yhdistettiin rehukomponenteittain. Rehujen kemialliset koostumukset analysoitiin Luken laboratoriossa Jokioisilla. Karkearehujen energia- ja valkuaisarvot laskettiin Luken (2017) kuvaamalla tavalla. Karkearehujen säilönnällinen laatu, kuitu ja sulamaton kuitu sekä väkirehujen rehuarvot analysoitiin Valion Seinäjoen laboratoriossa. Verinäytteistä määritettiin kalsiumpitoisuus kolorimetrisellä menetelmällä Movetin laboratoriossa Kuopiossa.

Tulosten laskentaan käytettiin ennen poikimista kunkin lehmän koko umpikauden keskiarvoja ja hiehoilta 60 viimeisen tiineyspäivän keskiarvoja. Poikimisen jälkeen tulosten laskentaan käytettiin 60 ensimmäisen laktaatiopäivän keskiarvoja. Koetulosten tilastolliseen käsittelyyn käytettiin SAS-ohjelmiston MIXED-proseduuria. Mallin kiinteät tekijät olivat ruokinta, poikimakerta (ensikot, toisen kerran poikivat, yli kaksi kertaa poikineet) ja rotu. Veren kalsiumpitoisuuden ja maitotuotoksen yhteyttä testattiin regressiomallilla, jossa selittävänä tekijänä oli ensimmäisen laktaatioviikon maitotuotoksen keskiarvo.

\section{Tulokset ja tulosten tarkastelu}

Kokoviljan kuiva-ainesato oli $8000 \mathrm{~kg} \mathrm{ha}^{-1}$ ja käytetyllä korjuutavalla jyvien varisemistappiot olivat vähäiset. Kokeen toteutusajankohta oli kokoviljasäilörehun kannalta haasteellinen. Lämpimän sään ja suuren avonaisen rehupinta-alan sekä olosuhteisiin nähden liian hitaan syöttönopeuden seurauksena kokoviljasäilörehu alkoi selvästi lämmetä siilossa. Lisäksi kokoviljasiilon pinnassa oli useita selvästi pilaantuneita kohtia. Koe-eläinten ruokinnassa käytetyn kokoviljan säilönnällinen laatu oli kuitenkin hyvä. Ainoastaan ammoniakkitypen ja liukoisen typen määrät olivat hieman tavoitearvoa korkeammat (taulukko 1). 
Taulukko 1. Koerehujen kemiallinen koostumus ja rehuarvot.

\begin{tabular}{|c|c|c|c|c|c|c|c|}
\hline & $\begin{array}{c}\text { Numisäi- } \\
\text { lörehu }\end{array}$ & $\begin{array}{l}\text { Kokovil- } \\
\text { jasäilörehu }\end{array}$ & Ohra & Rypsi & $\begin{array}{l}\text { Umpiki- } \\
\text { vennäinen }\end{array}$ & $\begin{array}{l}\text { Kokovil- } \\
\text { jaseos }\end{array}$ & $\begin{array}{c}\text { Nurmi+ }^{+} \\
\text {kivennäi- } \\
\text { nen }\end{array}$ \\
\hline Kuiva-aine, $\mathrm{g} \mathrm{kg}^{-1}$ & 314 & 301 & 886 & 898 & 972 & 330 & 328 \\
\hline Tuhka, $\mathrm{g} \mathrm{kg}^{-1} \mathrm{ka}$ & 91.2 & 59.3 & & & & & \\
\hline Raakavalkuainen, $\mathrm{g} \mathrm{kg}^{-1} \mathrm{ka}$ & 132 & 86.7 & 105 & 393 & & 118 & 130 \\
\hline Kuitu g kg-1 ka & 529 & 494 & & & & & \\
\hline Sulamaton kuitu g kg-1 ka & 76 & 148 & & & & & \\
\hline Tärkkelys, g kg ${ }^{-1}$ ka & & 154 & & & & & \\
\hline D-arvo, $\mathrm{g} \mathrm{kg}^{-1} \mathrm{ka}$ & 659 & 600 & & & & & \\
\hline ME, $\mathrm{g} \mathrm{kg}^{-1} \mathrm{ka}$ & 10.54 & 9.30 & 13.2 & 11.3 & & 9.39 & 10.36 \\
\hline OIV, $\mathrm{g} \mathrm{kg}^{-1} \mathrm{ka}$ & 78.2 & 70.7 & 96.6 & 173 & & 81.2 & 76.8 \\
\hline PVT, $\mathrm{g} \mathrm{kg}^{-1} \mathrm{ka}$ & 15.0 & -19.2 & -26.8 & 164 & & 0.73 & 14.7 \\
\hline Kalsium, g kg-1 ka & 4.35 & 2.07 & 0.66 & 7.53 & 44.3 & 3.24 & 4.97 \\
\hline Fosfori, $\mathrm{g} \mathrm{kg}^{-1} \mathrm{ka}$ & 3.18 & 2.33 & 3.56 & 11.4 & 40.0 & 3.81 & 3.76 \\
\hline Kalium, $\mathrm{g} \mathrm{kg}^{-1} \mathrm{ka}$ & 27.9 & 12.7 & 5.18 & 13.9 & 2.00 & 12.5 & 26.5 \\
\hline Magnesium, g kg-1 ka & 1.57 & 1.24 & 1.30 & 5.81 & 195 & 4.54 & 4.81 \\
\hline Natrium, $\mathrm{g} \mathrm{kg}^{-1} \mathrm{ka}$ & 0.15 & 0.10 & 0.098 & 1.10 & 106 & 1.75 & 1.93 \\
\hline Rikki, g kg ${ }^{-1}$ ka & 2.01 & 1.08 & 1.28 & 6.18 & 7.45 & 1.70 & 2.07 \\
\hline Kloori, g kg-1 ka & 6.94 & 3.31 & 0.53 & 0.54 & 186 & 5.65 & 9.88 \\
\hline DCAD-arvo, $\mathrm{mEq}^{\mathrm{kg}-1} \mathrm{ka}$ & 383 & 167 & 42 & 1.53 & -1066 & 132 & 357 \\
\hline \multicolumn{8}{|l|}{ Säilörehujen säilönnällinen laatu } \\
\hline $\mathrm{pH}$ & 3.98 & 3.71 & & & & & \\
\hline $\begin{array}{l}\text { Haihtuvat rasvahapot, } \\
\mathrm{g} \mathrm{kg}^{-1} \mathrm{ka}\end{array}$ & 6.5 & 9.75 & & & & & \\
\hline $\begin{array}{l}\text { Maito- ja muurahaishappo, } \\
\mathrm{g} \mathrm{kg}^{-1} \mathrm{ka}\end{array}$ & 56.3 & 47.8 & & & & & \\
\hline Sokeri, g kg-1 ka & 89.5 & 54.3 & & & & & \\
\hline Ammoniakkityppi, $\mathrm{g} \mathrm{kg}^{-1} \mathrm{ka}$ & 37.5 & 46.5 & & & & & \\
\hline Liukoinen typpi, $\mathrm{g} \mathrm{kg}^{-1} \mathrm{ka}$ & 448 & 519 & & & & & \\
\hline
\end{tabular}

$\mathrm{ME}=$ muuntokelpoinen enrgia

OIV=ohutsuolesta imeytyvä valkuainen

$\mathrm{PVT}=$ pötsin valkuaistase

$\mathrm{DCAD}=\left(\mathrm{K}^{+}+\mathrm{Na}^{+}\right)-\left(\mathrm{Cl}^{-}+\mathrm{S}^{2-}\right)$

Kokoviljasäilörehun D-arvo ja raakavalkuaispitoisuus olivat selvästi nurmisäilörehua matalammat, mikä on varsin tyypillistä kokoviljoille. Kokoviljaruokinnalla olleet lehmät saivat rypsiä keskimäärin 1,0 kg ka $\mathrm{pv}^{-1}$, joten koko dieetin PVT oli hieman positiivinen. Kokoviljaseoksen raakavalkuaispitoisuus oli $12 \mathrm{~g} \mathrm{~kg}^{-1} \mathrm{ka}$ nurmea matalampi, mutta OIV-pitoisuus jopa hieman nurmea korkeampi.

Kokoviljasäilörehun matalasta D-arvosta johtuen kokoviljaseoksen energiapitoisuus oli nurmea matalampi, mikä kompensoitiin tarjoamalla kokoviljaruokinnalla olleille eläimille enemmän rehua. Keskimääräinen kuiva-ainesyönti kokoviljaruokinnalla oli 10,4 $\mathrm{kg} \mathrm{pv}^{-1}$ ja nurmiruokinnalla 9,8 kg pv ${ }^{-1}$ Yleisesti lehmät söivät kaiken tarjolla olleen rehun, ja ilman ruokinnan rajoittamista rehunkulutus olisi oletettavasti ollut huomattavasti suurempaa. Rajoitettu ruokinta sekä se, etteivät kaikki eläimet päässeet saamaan aikaan syömään aiheutti selvästi stressiä ja streotyyppistä käyttäytymistä kuten kielenpyöritystä osalle eläimistä. Energian saanti kokoviljaseoksesta oli 89,3 $\mathrm{MJ} \mathrm{pv}^{-1}$ ja nurmesta 91,5 $\mathrm{MJ} \mathrm{pv}^{-1}$. Karkearehuseoksen 
lisäksi eläimet saivat kioskista tunnutusväkirehuannoksen, joten koko umpikauden keskimääräinen energian saanti oli molemmilla ruokinnoilla noin $100 \mathrm{MJ} \mathrm{ME} \mathrm{pv}^{-1}$.

Nurmisäilörehun kalsium- ja kaliumpitoisuudet olivat yli kaksinkertaiset kokoviljasäilörehuun verrattuna. Rehun kaliumpitoisuus vaikuttaa merkittävästi poikimahalvausriskiin ja saattaa olla jopa kalsiumia merkittävämpi tekijä (Horst ym. 1997). Korkeahkosta kaliumpitoisuudesta johtuen nurmidieetin DCAD-arvo oli lähemmäs $400 \mathrm{mEq} \mathrm{kg}{ }^{-1} \mathrm{ka}$. Kokoviljasäilörehun sekä kokoviljaseoksen DCAD oli yli $200 \mathrm{mEq} \mathrm{kg}^{-1} \mathrm{ka}$ nurmea matalampi. Tunnutuskaudella nurmiruokinnan DCAD-arvo oli keskimäärin $315 \mathrm{mEq} \mathrm{kg}{ }^{-1} \mathrm{ka} \mathrm{ja}^{-1}$ kokoviljaruokinnan $120 \mathrm{mEq} \mathrm{kg}{ }^{-1} \mathrm{ka}$. Vaikka kokoviljaruokinnalla DCAD oli selvästi nurmiruokintaa matalampi, oli se kuitenkin huomattavasti suurempi kuin poikimahalvauksen välttämiseksi suositeltu -50 $\mathrm{mEq} \mathrm{kg}{ }^{-1} \mathrm{ka}$.

Kaikkien koe-eläinten veren kalsiumpitoisuus oli normaalilla tasolla (2,1-2,5 mmol l-1) ennen poikimista. Poikimisen jälkeen kalsiumpitoisuudet laskivat keskimäärin 0,31 mmol $\mathrm{l}^{-1}$. Piilevä poikimahalvaus (Ca 1,4-2,0 $\mathrm{mmol} \mathrm{l}^{-1}$ ) oli 15 lehmällä. Yhdellä lehmällä veren kalsiumpitoisuus oli alle kliinisen poikimahalvauksen raja-arvon $\left(<1,4 \mathrm{mmol} \mathrm{l}^{-1}\right)$, mutta eläin ei vaatinut hoitoa poikimahalvauksen takia.

Poikimisen jälkeiseen veren kalsiumpitoisuuteen vaikutti odotetusti lehmän poikimakerta; useamman kerran poikineiden kalsiumpitoisuus oli merkittävästi ensikoita matalampi (kuva 1). Ensikoilla veren kalsiumpitoisuuden lasku oli keskimäärin vain $0,08 \mathrm{mmol} \mathrm{l}^{-1}$, kun taas yli kaksi kertaa poikineilla kalsiumpitoisuus laski 0,45 $\mathrm{mmol} \mathrm{l}^{-1}$. Piilevästä poikimahalvauksesta kärsi 38\% useamman kerran poikineista lehmistä, mikä on samaa luokkaa kuin aiemmissa tutkimuksissa on havaittu. Ensikoilla kalsiumpitoisuus ei laskenut normaalirajan alapuolelle. Ensikot eivät sairastu poikimahalvaukseen, mutta Reinhardtin ym. (2011) tutkimuksessa niistäkin peräti 25\% kärsi piilevästä poikimahalvauksesta.

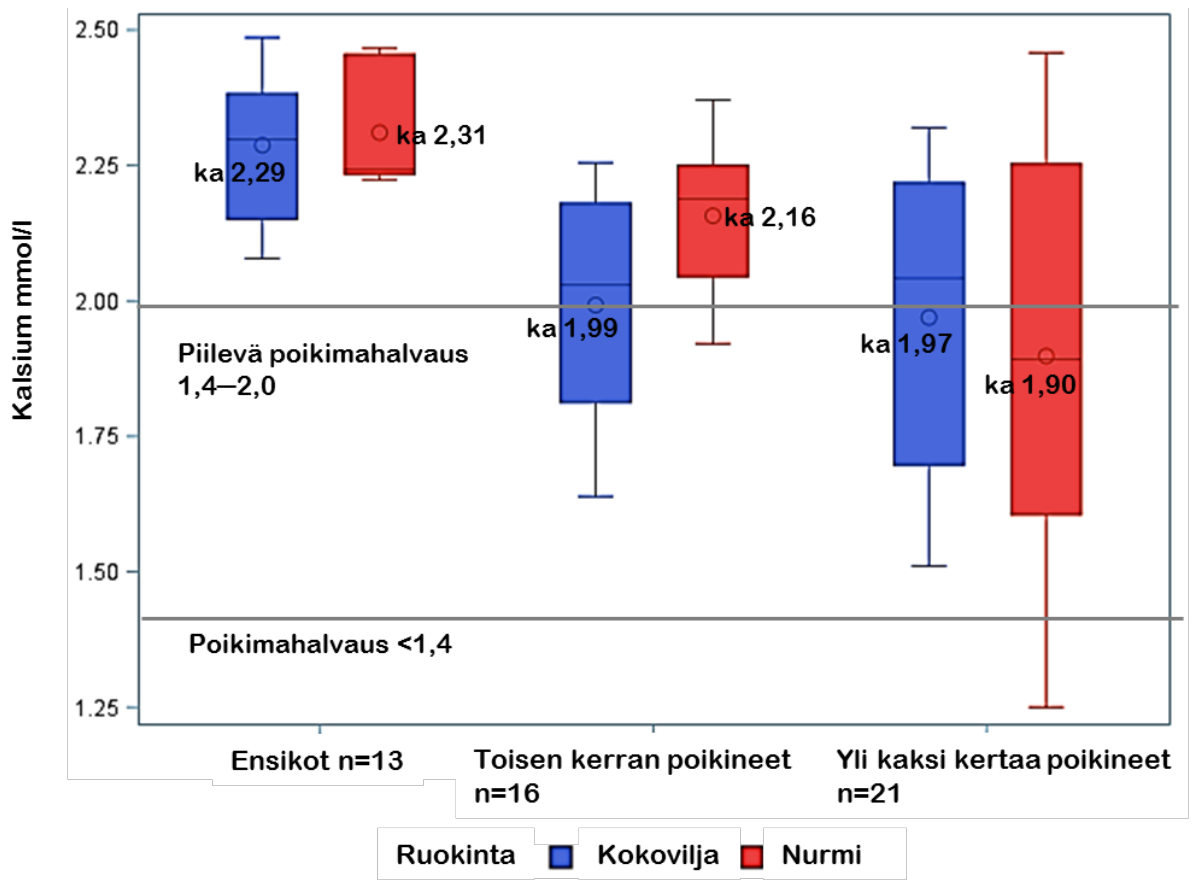

Kuva 1. Koelehmien veren kalsiumpitoisuudet poikimisen jälkeen. $\mathrm{o}=\operatorname{keskiarvo}(\mathrm{ka})$ 
Taulukko 2. Umpikauden ruokinnan vaikutus syöntiin, tuotokseen ja veren kalsiumpitoisuuteen.

\begin{tabular}{ccccc}
\hline & Nurmi & Kokovilja & SEM & $\begin{array}{c}\text { Tilastollinen } \\
\text { merkitsevyys }\end{array}$ \\
\hline Kalsium, mmol l-1 & & & & \\
Ennen poikimista & 2.39 & 2.37 & 0.025 & \\
Poikimisen jälkeen $_{\text {Syönti, kg ka pv }}^{-1}$ & 2.14 & 2.11 & 0.056 & \\
Umpikausi $_{\text {Alkulaktaatio }}$ & 9.8 & 10.4 & 0.15 & $* *$ \\
Maitotuotos, kg/pv & 19.9 & 19.3 & 0.38 & \\
\hline
\end{tabular}

Umpikauden ruokinnalla ei ollut vaikutusta poikimisen jälkeen mitattuun veren kalsiumpitoisuuteen (Taulukko 2). Piilevistä poikimahalvaustapauksista 6 oli nurmiruokinnalla ja 9 kokoviljaruokinnalla. Akuutista poikimahalvauksesta verinäytteen perusteella kärsinyt eläin oli nurmiruokinnalla. Umpikauden ruokinnalla ei ollut vaikutusta myöskään alkulypsykauden kuiva-ainesyöntiin tai maitotuotokseen.

Poikimisen jälkeistä veren kalsiumpitoisuuden laskua selitti parhaiten alkulypsykauden tuotos; kun ensimmäisen viikon keskimääräinen päivätuotos nousi yhden kilon, niin kalsiumpitoisuus laski 0,02 mmol/l. Poikimahalvaus on yhteydessä jalostuksen myötä lisääntyneeseen tuotantoon, esimerkiksi suomalaisissa karjoissa sairastavuusprosentti vaihteli tuotoksen mukaan välillä 4,3\% (tuotos $<6500 \mathrm{~kg} \mathrm{v}^{-1}$ ) $-7,3 \%$ (tuotos $>$ $9500 \mathrm{v}^{-1}$ ) (Pyörälä ja Tiihonen 2005).

\section{Johtopäätökset}

Kokoviljasäilörehu sopii hyvin umpikauden karkearehuksi, mutta tässä tutkimuksessa sen käyttö ei pienentänyt poikimahalvausriskiä tyypilliseen nurmisäilörehuruokintaan verrattuna. Kokoviljaruokinnan DCAD-arvo oli nurmea parempi, mutta silti huomattavasti positiivisempi kuin suositeltu tavoitearvo poikimahalvauksen välttämiseksi. Ruokinta oli lisäksi rajoitettua ja kaikki eläimet saivat oikean määrän umpikauden kivennäistä, jolloin molemmilla ruokinnoilla ns. haitallisten kivennäisten kokonaissaanti jäi kohtuulliseksi ja hyvien kivennäis- ja hivenaineiden saanti oli varmistettu. Rajoitettu ruokinta umpikaudella aiheuttaa kuitenkin eläimille stressiä ja lisää riskiä stereotyyppiseen käyttäytymiseen, joten parempi vaihtoehto on tarjota vähän energiaa sisältävää karkearehua vapaasti.

Poikimahalvaus on yhteydessä jalostuksen myötä lisääntyneeseen maitotuotokseen, joten veren kalsiumpitoisuuden laskua ja sitä kautta poikimahalvausriskiä lisää lehmän korkea tuotos ja nopea heruminen poikimisen jälkeen.

\section{Kirjallisuus}

Blanc, C., Van der List, M., Aly, S., Rossow, H. \& Silva-del-Río, N. 2014. Blood calcium dynamics after prophylactic treatment of subclinical hypocalcemia with oral or intravenous calcium. Journal of Dairy Science 97: 69016906.

Goff, J. 2014. Calcium and Magnesium Disorders. Veterinary Clinics of North America: Food Animal Practice 30: 359-381.

Horst, R., Goff, J., Reinhardt, T. \& Buxton, D. 1997. Strategies for Preventing Milk Fever in Dairy Cattle. Journal of Dairy Science 80: 1269-1280.

Goff, J. \& Horst, R. 2003. Role of acid-base physiology on the pathogenesis of parturient hypocalcaemia (milk fever) -the DCAD theory in principle and practice. Acta Veterinaria Scandinavica 97: 51-56. 
Lean, I., DeGaris, P., McNeil, D. \& Block E. 2006. Hypocalcemia in dairy cows: Meta-analysis and dietary cation anion difference theory revisited. Journal of Dairy Science 89: 669-684.

Lean, I., Saun, R. \& DeGaris, P. 2013. Mineral and antioxidant management of transition dairy cows. Veterinary Clinics of North America: Food Animal Practice 29: 367-386.

Pyörälä, S. \& Tiihonen, T. 2005. Nautojen sairaudet. Helsinki: Helsingin yliopisto. (Oppimateriaalia/Helsingin yliopisto, Eläinlääketieteellinen tiedekunta; 6).

Reinhardt T., Lippolis J., McCluskey B., Goff J. \& Horst R. 2011. Prevalence of subclinical hypocalcemia in dairy herds. The Veterinary Journal 188: 122-124.

Saarijärvi, K. \& Kananen, M. 2013. Umpikaudelle oikea rehu. KMVET Kotieläinten terveydenhoitolehti 3/13. Otavamedia. 